\title{
Víctor Brangier y María Elisa Fernández. Historia cultural hoy, trece entradas desde América Latina, Rosario, Prohistoria, 2019, 348 págs.
}

En una conferencia en el año 2001, impartida en el Instituto Mora de México, titulada Cultural History and his Neighbors, el historiador Peter Burke reconoció cuán complejo era definir en pocas palabras lo que conocemos como historia cultural. A través de una revisión de los orígenes, de la trayectoria y de la evolución que ha tenido este concepto, Burke da cuenta de que al aproximarnos a dicho término, nos encontramos con un amplio mundo de definiciones, enfoques e ideas, que en suma construyen la variante cultural de lo histórico, aspecto que en las últimas décadas ha vivido un desarrollo importante $\mathrm{y}$ que sigue ofreciendo nuevos elementos para su enriquecimiento.

El análisis que desde lo planteado por Burke podemos hacer sobre el significado e implicancias de esta corriente historiográfica, permite reconocer de inmediato que su amplitud le entrega riqueza y puntos de vista para abordar las acepciones que tenemos acerca de la historia cultural. Dicha sensación se percibe de inmediato al momento de conocer Historia cultural hoy, trece entradas desde América Latina, libro pensado y coeditado por Victor Brangier y María Elisa Fernández, quienes, a través de un esfuerzo encomiable, lograron reunir en sus páginas a diversos autores del continente, los cuales en con- junto entregan trece escritos que no hacen más que ampliar las variantes que posee la historia cultural, además de enriquecer de gran forma su definición.

Una primera parte del texto, compuesta por cuatro trabajos, lleva como título Historia cultural en movimiento. A través de diversos enfoques, los autores dan a conocer detalles acerca de su surgimiento en Europa y su recepción en Latinoamérica. Sin duda que estos escritos otorgan al libro los soportes teóricos necesarios, tanto para entender lo que significa la historia cultural, como para comprender la forma en que dichas ideas fluyeron hacia nuestro continente.

Además, cabe señalar que estos trabajos se hacen particularmente interesantes de leer y analizar, por la complejidad dentro del análisis presentado. Carlos Aguirre es el autor del primer escrito de esta obra, en el que, dentro de un acucioso análisis, ofrece un panorama general de la historia cultural y sus flujos e influencia entre Europa y nuestros países vecinos, junto a la forma en que dichos preceptos se plasmaron en territorio latinoamericano. Tal aspecto es recogido por Julio Bentivoglio y Mariana Canavese en el segundo y tercer escrito del libro. Mientras el primero se centra en Brasil y en su historiogra-

Jorge L. Gaete

Víctor Brangier y María Elisa Fernández. Historia cultural hoy, trece entradas desde América Latina, Rosario, Prohistoria, 2019,348 págs. Autoctonía. Revista de Ciencias Sociales e Historia, Vol. III, N² 2, Julio-Diciembre 2019, 289-292

ISSN 0719-8213

DOI: http://doi.org/10.23854/autoc.v3i2.130 
fía local, para dar a conocer la forma en que influyó la historia cultural en este país, la segunda enfatiza su estudio en Michel Foucault y su recepción a través de un paralelo que realiza con la historia intelectual, término que aborda de manera tal que permite establecer diferencias con la historia cultural.

A este grupo de trabajos los complementa de gran manera el escrito de Max Hering, cuarto y último escrito de esta primera parte del libro. Su análisis se centra en el siempre llamativo campo de la microhistoria, término que Clifford Geertz, Carlo Ginzburg y Natalie Zemon Davis han acuñado en sus estudios. En dicho trabajo, Hering presenta las principales características de esta corriente, realzando cómo la historia cultural la ha posesionado como una variante historiográfica con un concepto propio.

Más adelante, el libro presenta una segunda sección, que lleva por título La cultura en tensión: imaginarios negociados y hegemonías disputadas. $\mathrm{Al}$ contrario del apartado anterior, que tiene un énfasis más teórico, esta parte del libro tiene como propósito, a lo largo de sus cuatro trabajos, poner en práctica la idea de historia cultural, muy cercana a lo definido por Geertz: dar a conocer la relación entre significantes y sus significados, realzando el papel de los símbolos, entendidos como un sistema de concepciones expresadas que en conjunto influyen en la forma en que la gente conoce y actúa en la vida.

La riqueza temática de este apartado es evidente y queda de manifiesto al momento de conocer su contenido. Los escritos se diferencian entre sí en cuanto a marcos temporales y temáticas. María José Correa inicia esta sección estudiando a los médicos de fines del siglo XIX y comienzos del $\mathrm{XX}, \mathrm{y}$ al sistema publicitario y de consumo que en torno a ellos y a las medicinas se generó. Por su parte, Dulce Aguirre nos entrega un análisis enfocado en el ensayo $\mathrm{F}$ for Fake de Orson Welles, que desarrolla la historia del falsificador húngaro de obras artísticas Elmyr de Hory, trabajo en el que centra su mirada en el gusto, la industria artística y las apreciaciones acerca de los objetos culturales. Si bien ambos trabajos difieren en cuando a temas de estudios, ambos comparten la influencia de los símbolos y las concepciones culturales que de ellos provienen.

En cuanto a los trabajos de Valeria Manzano e Inés Pérez, estos tienen a Argentina como epicentro de sus análisis. Mientras Manzano se enfoca en la juventud, su accionar y el significado de ser joven, en un sentido político en este país durante la década de 1980, Pérez propone un sugerente estudio para comprender a la clase, término frecuentemente utilizado por la historia social, desde el terreno de lo cultural, con lo que se sumerge en un campo donde resaltan miradas e identidades en torno a la construcción de la clase. Estos escritos logran recoger en gran medida las apropiaciones, los discursos y los símbolos que posee el significado de ser joven y de pertenecer a una clase, temas que les permiten dar una mirada hacia lo que ha sido la Argentina del siglo XX. 
La tercera parte y final de este libro, Textos y contextos, usos sociales y políticos de las representaciones, retoma los símbolos enfocándose en el uso y en la forma en que ellos permitieron cumplir con los objetivos trazados por los protagonistas de los temas en que los cinco trabajos que componen este apartado se enfocan. De ellos, los dos primeros nos llevan a la época colonial. Eugenia Bridikhina se centra en la cultura cortesana en América y en la vida de las cortes virreinales, estudio en el que, utilizando elementos políticos, aborda el poder, la ritualidad y los símbolos en este período. Por su parte, Paola Revilla se centra en el caso de Esperanza de Robles, esclava liberta de La Plata, en Charcas, entre finales del siglo XVI y comienzos del XVII. A través de un gran trabajo documental, la autora centra su mirada en el desenvolvimiento en la sociedad colonial platense y en el uso de capitales simbólicos que realizó en su interior, lo que permite inferir, junto al trabajo anterior, las aplicaciones que esta mirada culturalista tiene para realizar aproximaciones históricas hacia sujetos como los aquí señalados. Posteriormente, Víctor Brangier acentúa su análisis en los testigos de los expedientes judiciales y su actuar al momento de desarrollarse dichos conflictos, lo que una vez más reitera la relevancia de este enfoque cultural con el que se mira a los documentos. A través de una lectura entre líneas, y dotado de gran perspicacia al momento de aterrizar los conflictos judiciales, evitando al mismo tiempo caer en la mera acumulación de datos, Brangier utiliza lecturas discursivas para comprender el actuar que tuvieron aquellos sujetos involucra- dos en estos procesos, con lo que logra establecer un importante aporte temático a la historia de la justicia.

Los dos últimos trabajos se esta sección y del libro tienen como escenario a Bolivia y Chile. Paula Peña aborda la ciudad boliviana de Santa Cruz, su identidad, su relación con el resto del país en medio de los conflictos permanentes entre las regiones que lo componen, y se centra en su memoria colectiva entre los años 1900 y 1925, en medio de las relaciones que tuvo esta zona con el gobierno central. Por otra parte, María Elisa Fernández analiza el voto femenino en Chile entre 1952 y 1958, como una forma de aproximarse a las electoras y a los discursos que siguieron en torno a la figura de Carlos Ibáñez del Campo. Ambos escritos tienen en común la construcción de identidades a partir de redes simbólicas.

En suma, el análisis de este libro permite afirmar, una vez más, lo importante que es establecer diálogos al interior de la disciplina, sobre todo al momento de elaborar productos historiográficos de esta naturaleza. La identificación del problema estudiado desde diversas perspectivas, el reunir posiciones y, en conjunto, poder establecer aproximaciones para resolverlo, permite enriquecer el debate, conocer el tema desde una mayor profundidad, y sobre todo entenderlo desde una perspectiva multidimensional. Dichos aspectos se cumplen a cabalidad en el presente texto, en el que la historia cultural es expuesta desde sus bases teóricas hasta algunas 
de sus múltiples puestas en práctica.

Por otra parte, es de resaltar el trabajo de edición existente tras esta propuesta. Recibir tal cantidad de trabajos y darles coherencia, para que sean capaces de encajar como piezas de un rompecabezas, es una labor compleja. Para quienes hemos vivido una experiencia similar, sabemos que dicho trabajo es arduo, que no está exento de conflictos. También es un trabajo que queda sujeto a múltiples correcciones, para dar a los aportes una dirección similar, lo que si bien suele ralentizar la concreción del mismo, trae al mismo tiempo grandes resultados. Frente a esto, felicitamos a Víctor Brangier y María Elisa Fernández por la labor que realizaron en pos de esta obra, y por el esfuerzo de establecer lazos con investigadores de diversos países del continente, quienes por fortuna accedieron a formar parte de esta propuesta.

Con todo lo señalado, podemos concluir que el presente libro cumple su objetivo de exponer, a través de sus trece propuestas, un panorama acerca de la situación del desarrollo que ha tenido la historia cultural en América Latina, junto con la situación en la que actualmente se encuentra hoy. Al tenerlo en sus manos, el lector y sobre todo el investigador podrán tener acceso a un interesante libro y material de trabajo cuyos méritos lo transforman en un texto valioso de poseer en las bibliotecas personales.

Jorge L. Gaete

Universidad Andrés Bello

Centro de Estudios Bicentenario 